\title{
Attached cultivation for improving the biomass productivity of Spirulina platensis
}

\author{
Zhang Lanlan $^{\mathrm{a}, \mathrm{b}}$, Chen Lin ${ }^{\mathrm{b}}$, Wang Junfeng ${ }^{\mathrm{b}}$, Chen Yu ${ }^{\mathrm{b}}$, Gao Xin ${ }^{\mathrm{a}}$, Zhang Zhaohui ${ }^{\mathrm{a}, *}$, Liu Tianzhong ${ }^{\mathrm{b}, 1}$ \\ ${ }^{a}$ College of Food Science and Engineering, Ocean University of China, Qingdao, Shandong 266101, PR China \\ ${ }^{\mathrm{b}}$ Key Laboratory of Biofuels, Qingdao Institute of Bioenergy and Bioprocess Technology, Chinese Academy of Sciences, Qingdao, Shandong 266101, PR China
}

\section{H I G H L I G H T S}

- Spirulina platensis was successfully cultivated in attached biofilm.

- Electrostatic flocking cloth is a practicable industrial substratum.

- Biomass productivity of $60 \mathrm{~g} \mathrm{~m}^{-2} \mathrm{~d}^{-1}$ was obtained in an outdoor bench.

\section{A R T I C L E I N F O}

\section{Article history:}

Received 17 November 2014

Received in revised form 6 January 2015

Accepted 8 January 2015

Available online 20 January 2015

\section{Keywords:}

Spirulina platensis

Attached cultivation

Biomass productivity

Outdoor bench-scale cultivation

\section{G R A P H I C A L A B S T R A C T}

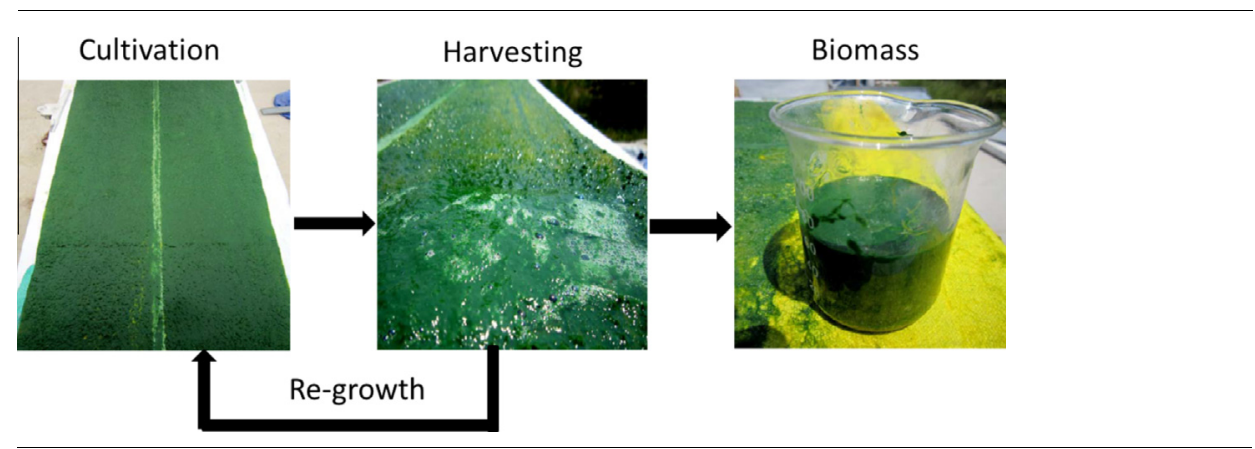

\begin{abstract}
A B S T R A C T
To improve cultivation efficiency for microalgae Spirulina platensis is related to increase its potential use as food source and as an effective alternative for $\mathrm{CO}_{2}$ fixation. The present work attempted to establish a technique, namely attached cultivation, for S. platensis. Laboratory experiments were made firstly to investigate optimal conditions on attached cultivation. The optimal conditions were found: $25 \mathrm{~g} \mathrm{~m}^{-2}$ for initial inoculum density using electrostatic flocking cloth as substrata, light intensity lower than $200 \mu \mathrm{mol} \mathrm{m}{ }^{-2} \mathrm{~s}^{-1}, \mathrm{CO}_{2}$ enriched air flow (0.5\%) at a superficial aeration rate of $0.0056 \mathrm{~m} \mathrm{~s}^{-1}$ in a $\mathrm{NaHCO}_{3}-$ free Zarrouk medium. An outdoor attached cultivation bench-scale bioreactor was built and a $10 \mathrm{~d}$ culture of S. platensis was carried out with daily harvesting. A high footprint areal biomass productivity of $60 \mathrm{~g} \mathrm{~m}^{-2} \mathrm{~d}^{-1}$ was obtained. The nutrition of $S$. platensis with attached cultivation is identical to that with conventional liquid cultivation.
\end{abstract}

(c) 2015 Elsevier Ltd. All rights reserved.

\section{Introduction}

In recent years, the global concern on greenhouse effect has driven a variety of attempts to reduce gas emissions by fixation of $\mathrm{CO}_{2}$. Microalgae have been thought to be an effective way to solve this problem because of their concomitant capacity to fix $\mathrm{CO}_{2}$ into algal biomass through photosynthesis and potentially produce

\footnotetext{
* Corresponding author. Tel./fax: +86 53282031936.

E-mail addresses: zhangzhh@ouc.edu.cn (Z. Zhang), liutz@qibebt.ac.cn (T. Liu).

1 Tel./fax: +8653280662735.
}

biodiesel (Wijffels and Barbosa, 2010). In order to make this process economically feasible and environmentally sustainable, the premise is represented by the large-scale production of microalgae biomass efficiently at low cost (Larkum, 2010). Spirulina sp., one of the most popularly cultivated microalgae, has been widely used as a healthy food, forage and additive since the 1970s (Hu et al., 1998; Jimenez et al., 2003), due to its rich nutrients including proteins, polyunsaturated fatty acids, polysaccharides, carotenoids and vitamins (Belay et al., 1993; Madkour et al., 2012). Though the commercialized production of Spirulina sp., as healthy food and valued additives is profitable, more efficient cultivation technique 
in pursuit of lower cost is also currently an important direction, especially in order to enlarge the usage of Spirulina sp.

To date, the commercial production of Spirulina sp. is carried out almost exclusively in open ponds, which are easy to build and do not require particular control of some parameters such as illumination and temperature. However, the drawback of these systems is the low biomass productivity, less than $15 \mathrm{~g} \mathrm{~m}^{-2} \mathrm{~d}^{-1}$ (Jimenez et al., 2003; De Bhowmick et al., 2014). Furthermore, in open ponds, there were other drawbacks, such as the difficulty of reaching very high biomass concentration due to difficultly maintaining optimal cultivation parameters, the easiness of contamination and the serious water evaporation between ponds and surrounding environments (Guterman et al., 1990). Another cultivation way of Spirulina sp. is the use of a variety of enclosed photobioreactors (PBRs) including bubbling column, airlift reactor, tubular, panel and plastic bags (Lee, 1986; Converti et al., 2006). These culture systems showed a better control of nutrients, light exposition and carbon absorption, as well as contamination avoidance resulting in cultures more dense, a little higher biomass productivity and a better quality of products than those reached in open ponds. Conversely, PBRs are characterized by high cost for their construction and by difficulty in system maintenance (Chen et al., 2011).

In a word, Spirulina sp., certainly with other microalgae, is usually cultivated in water suspension, hence it suffered a fragility of the cell sheath and the filamentous morphology response to shear force due to stirring and bubbling in suspended cultivation (Tomaselli et al., 1981). However, beside of grown in water suspension, some microalgae are capable to grow as productive biofilms over substrata (Wuertz et al., 2003). This pattern of growth may be able to solve the technical defects in liquid suspension culture, and thus disinhibit biological limitation for culturing Spirulina sp. therein.

Recently, a novel technology for microalgal biofilm cultivation, namely attached cultivation has been announced (Liu et al., 2013). Since then, more and more attentions have been paid on applicability of this technology and developing derivative technologies. With such technologies, a diverse of algal strains have been cultivated (Shen et al., 2014; Naumann et al., 2013; Blanken et al., 2014; Gross and Wen, 2014; Shi et al., 2014). Among of which, the best biomass productivity was $80 \mathrm{~g} \mathrm{~m}^{-2} \mathrm{~d}^{-1}$, obtained with the oleaginous microalgae Aucutodesmus obliquus, which was $700 \%$ higher than that obtained with conventional open ponds under the same climate and light conditions (Liu et al., 2013). Beside of high biomass productivity, potential in reducing harvesting-cost and power consumptions have been concluded (Liu et al., 2013; Ji et al., 2014a; Ozkan et al., 2012). The improvement of cultivation technology to enhance the biomass productivity and to reduce the cost associated to its production is beneficial for the expansion of this application. However, no attempts have been reported before on cultivation of Spirulina sp. with this technique.

The present work is to implement an attached cultivation technique for Spirulina platensis. The purpose lies in technological conditions of optimal cultivation, and the expansion of scale in outdoor environment. In order to reach this goal, firstly indoor experiments were carried out to clear the influence of cultivation conditions, such as initial inoculation density, light intensity, carbon supplementation by $\mathrm{CO}_{2}$ aeration and substrata materials, on the growth of attached $S$. platensis biofilm. Later, an outdoor attached cultivation bench bioreactor was constructed and a $10 \mathrm{~d}$ attached cultivation practice was carried out. Results have shown that the attached cultivation was effective to significantly improve the biomass productivity for S. platensis.

\section{Methods}

\subsection{Microalgae strain and culture medium}

The microalga S. platensis was purchased from the Institute of Oceanology, Chinese Academy of Sciences, PR China. The strain as inoculum for attached cultivation experiments was grown in a Zarrouk medium (Zarrouk, 1966). Bubbling glass columns $(0.5 \mathrm{~m}$ long, $0.05 \mathrm{~m}$ in inner diameter with $0.007 \mathrm{~m}^{-3}$ working volume) were used, and aerated with $1 \% \mathrm{CO}_{2}(\mathrm{v} / \mathrm{v})$ enriched air at $0.25 \mathrm{vvm}$ (volume/volume per minute), under a continuous illumination of $100 \mu \mathrm{mol} \mathrm{m} \mathrm{m}^{-2} \mathrm{~s}^{-1}$, and maintained a temperature of $25 \pm 1^{\circ} \mathrm{C}$ for $6 \mathrm{~d}$.

\subsection{Attached cultivation}

\subsubsection{Indoor experiments}

The attached cultivation bioreactor used in indoor experiments, which is shown in Fig. 1A, was similar to that used by Liu et al.
A

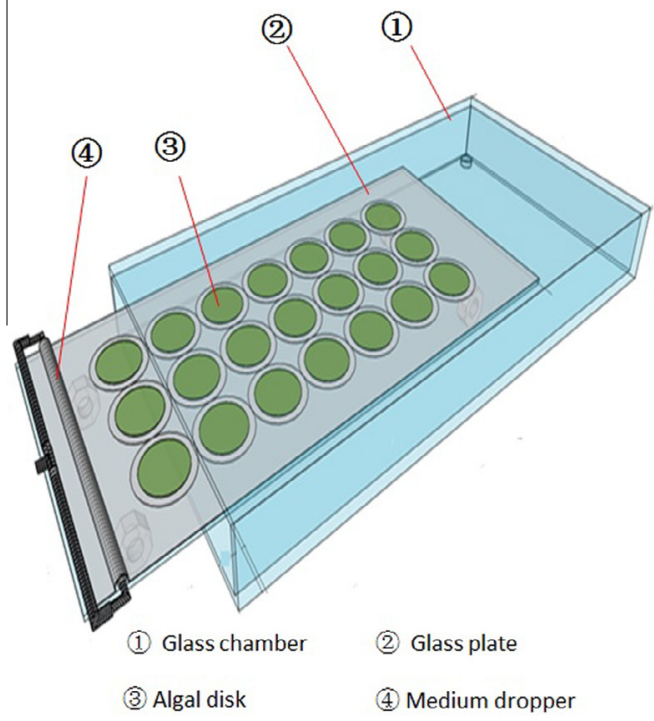

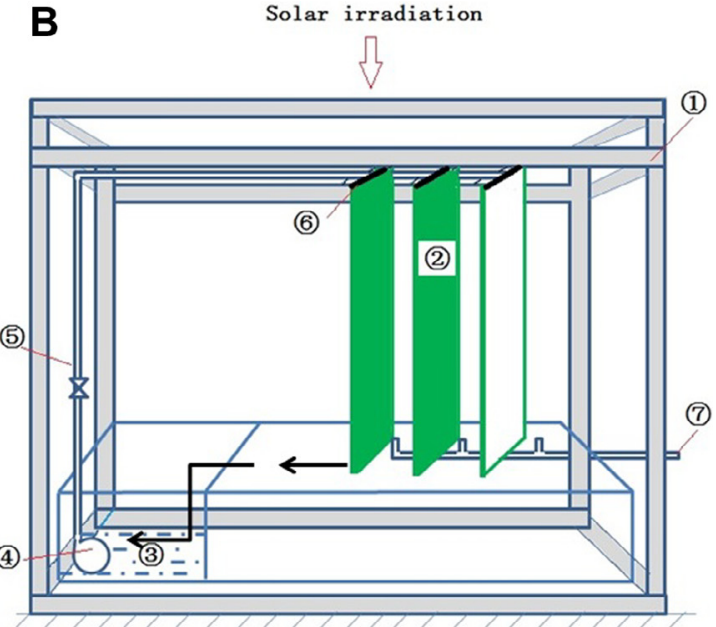

(1) Steel frame (2) Culturing substratum (3) Medium reservoir (4) Water pump (5) Circulation pipe (6) Medium sprayer (7) $\mathrm{CO}_{2}$ enriched gas

Fig. 1. Schematic diagram of the attached cultivation bioreactor for S. platensis. (A) Laboratory device. (B) Outdoor bench-scale bioreactor. 
(2013) and by Ji et al. (2014b). Roughly, a glass plate (0.3 m long, $0.2 \mathrm{~m}$ wide), covered by a piece of equal-sized cellulose filter paper, and was placed in the center of a glass chamber $(0.5 \mathrm{~m}$ long, $0.25 \mathrm{~m}$ wide and $0.05 \mathrm{~m}$ high). A certain volume of algal inoculum was evenly filtered through a nitrate/acetate cellulose (NC) membrane (pore size $0.45 \mu \mathrm{m}$; Motimo Co., China) to form an "algal disk" with $0.001 \mathrm{~m}^{2}$ footprint. Then the prepared "algal disks" were evenly distributed on the glass plate. The algal disks were grown under artificial light provided by cold white fluorescence lamps (FSL T8 36W, Foshan Electrical Lighting Co., Ltd., China), which were installed above the glass chamber. $\mathrm{A} \mathrm{NaHCO}_{3}$-free Zarrouk medium was supplied to "algal disk" via a perforated polyurethane tube connected with a mini peristaltic pump (TP12DC 12V, Guangzhou JU PlasFitting Technology Co., Ltd., China), to keep it well wetted but to avoid being washed off by carefully controlling medium dropping rate.

The initial inoculation density of the "algal disk" was controlled by adjusting the volume of suspended cultures filtered on the NC membrane.

To investigate the influence of light intensity on S. platensis growth performances, light intensities were adjusted by varying the distance between the lamps and the cultivated surface.

Compressed air with different concentrations of $\mathrm{CO}_{2}$ was supplied into the glass chamber via a nozzle installed at the bottom of the chamber, with a superficial aeration rate of $0.0056 \mathrm{~m} \mathrm{~s}^{-1}$, unless otherwise stated.

In addition of NC membrane, four industrial substrata materials, including electrostatic flocking cloth (EFC), foam sponge (FS), fiber carpet (FC) and superfine fiber towel (SFT), were evaluated, to look for an industry-possible substratum for later outdoor cultivation. The EFC consisted of short polyamide fibers ( $4.0 \mathrm{~mm}$ length) flocked onto a textile substrate, purchased from (Jinfengshen products Co., Ltd., Shenzheng, China). The FS was made from polyester, full of many pores of average diameter $2 \mathrm{~mm}$. The FC and SFT were purchased from local market. For indoor experiments, each substratum was cut into a $0.032 \mathrm{~m}$ square, with a footprint of $0.001 \mathrm{~m}^{2}$. The inoculation on these four substrata were applied by dabbing certain volume of dense algal slurry until $25 \mathrm{~g} \mathrm{~m}^{-2}$, to reach a complete coverage of the substrata surface based on preliminarily experiment.

Three "algal disks" for each cultivation conditions were sampled on day 1 and day 3 to determine biomass productivity.

\subsubsection{Outdoor cultivation practice}

The outdoor bench-scale bioreactor, as shown in Fig. 1B, was a descendant of indoor cultivation bioreactor, but was designed referred to a multi-plates modules by Liu et al. (2013). The reactor consisted of three pieces of double-sides EFC, a medium sprayer and a $\mathrm{CO}_{2}$ injector, all of which were installed in a steel frame with $1.5 \mathrm{~m}$ length, $0.3 \mathrm{~m}$ width and $1.3 \mathrm{~m}$ height. The top surface of this reactor was covered by a transparent polyethylene film, but the four side surfaces were covered by non-transparent nonwoven fabrics to shade light coming from the surrounding environment. Each of EFC ( $1.0 \mathrm{~m}$ height and $0.2 \mathrm{~m}$ width) was vertically and parallel hanged with a distance of $0.2 \mathrm{~m}$ between neighboring pieces, inside of the frame.

The inoculation of S. platensis on EFC for outdoor cultivation was same as indoor one, by dabbing certain volume of dense algal slurry until $25 \mathrm{~g} \mathrm{~m}^{-2}$ to make completely covered and even distributed with algal cells. Only indicated sides of EFC, were inoculated.

The algal cells on EFC were wetted with same medium as indoor experiment via a sprayer, which was made of a plastic pipe with holes $(\varphi 1 \mathrm{~mm})$ every $5 \mathrm{~cm}$ and tightly fixed at the top edge of each cloth. The medium flow rate was monitored to keep the EFC well wetted but not soaked.
$\mathrm{CO}_{2}$ enriched compressed air (air: $\mathrm{CO}_{2}=1: 0.01, v: v$ ) was supplied into the reactor, with a superficial aeration rate of $0.0056 \mathrm{~m} \mathrm{~s}^{-1}$, through a plastic pipe installed at the left bottom of the steel frame. The $\mathrm{CO}_{2}$ concentration of aerated gas was doubled of the indoor values, due to consider the fact that the reactor was not well sealed and the cultivation space is far bigger than that occupied by the three EFCs.

The algal film was sampled by gently manual scraping of the substrata surface with a soft rubber blade from each surface of the clothes at 6:00 pm every day. The residual biomass was left behind to act as inoculums for the next day's growth cycle. The harvested algal slurry was twice washed with distilled water, and then was oven-dried for biomass productivity measurement.

All the outdoor bench experimental cultivations were carried out in the campus of Qingdao Institute of Bioenergy and Bioprocess Technology, Chinese Academy of Sciences (35⒊ $35^{\prime} \mathrm{N}, 119^{\circ} 30^{\prime} \mathrm{E}$ ) during May 21 to 30, 2012. The photon flux density (PFD) was measured using a photometer (LI-250A, LI-COR Co., Ltd., USA) every hour from 6 am to $6 \mathrm{pm}$ every day and the simple averaged value is calculated to present the PAR (photosynthetic active radiation). Meanwhile, the atmosphere temperature in the cultivation cavity was also recorded. A certain volume of distilled water was added to the medium reservoir to compensate the water loss by evaporation every day.

\subsection{Growth analysis}

The biomass productivity $\left(P, \mathrm{~g} \mathrm{~m}^{-2} \mathrm{~d}^{-1}\right)$ was measured with gravimetric method. The algal cells were totally washed off from the "algal disk" using distilled water. For outdoor experiments, algal cells were collected from the whole surface of each EFC for gravimetric measurement, using a same protocol as indoor experiments. The collected algal cells were then filtered on a preweighted $\left(W_{0}, \mathrm{~g}\right) \mathrm{NC}$ membrane (pore size $\left.0.45 \mu \mathrm{m}\right)$. The algal paste was washed twice with distilled water to remove all soluble nutrients. The membrane was then oven-dried for $12 \mathrm{~h}$ at $105^{\circ} \mathrm{C}$ and then weighted $\left(W_{\mathrm{n}}, \mathrm{g}\right)$ after cool down.

The biomass productivity based on unit area of the substrate after $n$ days culture $\left(P_{\mathrm{g}, \mathrm{n}}, \mathrm{g} \mathrm{m}^{-2} \mathrm{~d}^{-1}\right)$ is calculated as shown in Eq. (1):

$P_{\mathrm{g}, \mathrm{n}}\left(\mathrm{g} \mathrm{m}^{-2} \mathrm{~d}^{-1}\right)=\left(W_{\mathrm{n}}-W_{0}\right) /\left(A_{\mathrm{g}} \times n\right)$

where the $A_{\mathrm{g}}$ was $0.001 \mathrm{~m}^{2}$ for indoor experiments, and was $0.2 \mathrm{~m}^{2}$ for outdoor experiments. The surface area of EFC $(1.0 \mathrm{~m} \times 0.2 \mathrm{~m})$.

The biomass productivity based on footprint area of the bioreactor after $n$ days culture $\left(P_{\mathrm{f}, \mathrm{n}}, \mathrm{g} \mathrm{m}^{-2} \mathrm{~d}^{-1}\right)$ is calculated as shown in Eq. (2).

$P_{\mathrm{f}, \mathrm{n}}\left(\mathrm{g} \mathrm{m}^{-2} \mathrm{~d}^{-1}\right)=\sum\left(W_{\mathrm{n}}-W_{0}\right) /\left(A_{\mathrm{f}} \times n\right)$

where $\sum$ indicated the summary weight of algal cells from all four cultivation sides of EFC, $A_{\mathrm{f}}$ was the footprint area occupied by the four cultivation surfaces $(0.2 \mathrm{~m} \times 0.4 \mathrm{~m})$, which could also be taken as the incidence light area.

\subsection{Nutrient analysis}

In order to carry out nutrient analysis, microalgae were harvested and first filtered and washed with plenty of de-ionized water. Later, the harvested biomass was lyophilized, then sealed and finally stored in the dark at $-20^{\circ} \mathrm{C}$ before measurement.

Carbohydrates were determined colorimetrically (Cary50, Varain, USA) with the use of phenol-sulfuric acid (Dubois et al., 1956 and glucose as standard.

Protein content of $S$. platensis was analyzed by the Kjeldhal method (AOAC, 1984), using 6.25 as a conversion factor. 
Total lipids were estimated gravimetrically according to the method of Chen et al. (2012), later modified by Guo et al. (2014).

\section{Results and discussions}

\subsection{The influence of initial inoculation density}

Fig. 2 reported the changes of the biomass productivity of S. platensis biofilm with different initial inoculum densities. It can be found the biomass productivity, both at the first day and the third day, increased till to the maximum values of 12 and $8.03 \mathrm{~g} \mathrm{~m}^{-2} \mathrm{~d}^{-1}$, respectively, with $7-11 \mathrm{~g} \mathrm{~m}^{-2}$ as initial inoculum density, then the biomass productivity declined. It indicates that this range represents the appropriate initial inoculation density as reported for similar results obtained by other researches. The biomass productivity of Pseudochlorococcum sp. increased with the increasing of initial inoculation density, and the maximum biomass productivity of $6.0 \mathrm{~g} \mathrm{~m}^{-2} \mathrm{~d}^{-1}$ occurred at the initial inoculation density of $3-5 \mathrm{~g} \mathrm{~m}^{-2}$ (Ji et al., 2014a). A higher initial inoculation density of $8-10 \mathrm{~g} \mathrm{~m}^{-2}$ was reported to be appropriate for Aucutodesmus obliquus (Ji et al., 2014b). These results showed how different microalgae species have different optimal inoculation density even if the difference is not too big when using a same NC membrane substrata.

The influence of initial inoculation density reflects the penetration path of light to the biofilm. Light can penetrate the algal biofilm to a few dozens of microns with an irradiation intensity of $100 \mu \mathrm{mol} \mathrm{m}^{-2} \mathrm{~s}^{-1}$ as in this case (Ji et al., 2014a). When the initial inoculation density is very low, less algal cells (or a thinner biofilm) than those that can be penetrated by the light are involved in the photosynthesis. A thicker biofilm with the appropriate initial inoculation density means that more algal cells participate to the growth. However, it should be considered that when a high inoculum is used, the algal cells at the top layer of the substrata surface can be easily penetrated by the light, while the algal cells residing on the lower strata could lose their biomass due to respirations and disable to capture enough light for the biomass accumulation.

It also can be found that the cultivation on the first day had higher biomass productivity than the averaged value during the $3 \mathrm{~d}$, indicating that the biomass productivity declined with the prolongation of the attached cultivation. A possible explanation could also be attributed to "renewed" inoculum, of which the thickness

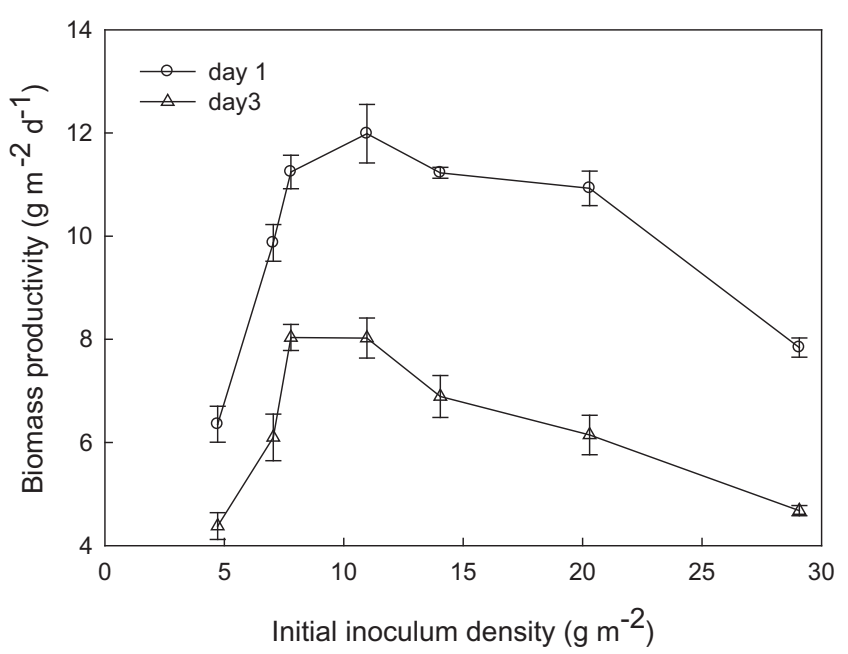

Fig. 2. Effects of initial inoculum density on the biomass productivity of attached $S$. platensis biofilm. Culture conditions: $100 \mu \mathrm{mol} \mathrm{m} \mathrm{m}^{-2} \mathrm{~s}^{-1}$ light intensity, $\mathrm{CO}_{2}$ enriched air $(0.5 \%)$ at $0.0056 \mathrm{~m} \mathrm{~s}^{-1}$ superficial aeration rate, room temperature, $3 \mathrm{~d}$ of cultivation. Data and error bars represent means \pm SD of three repeats. becomes thicker day by day by growth. Because of that, a prompt harvest at an appropriate frequency is suggested to slow down the reduction of biomass productivity and help to approach high biomass yield.

\subsection{The influence of photon flux density (PFD)}

The PFD is reported to significantly affects both biomass production and the metabolic activity of Spirulina sp. (Soletto et al., 2005; Ajayan and Selvaraju, 2011; Bezerra et al., 2012). The relationship between PFD and biomass productivity of S. platensis in biofilm cultivation was plotted in Fig. 3 . The biomass productivity linearly increased as the PFD rose. The maximum biomass productivity value of 18 and $14 \mathrm{~g} \mathrm{~m}^{-2} \mathrm{~d}^{-1}$ has been achieved on day 1 and day 3 , respectively with a PFD of $200 \mu \mathrm{mol} \mathrm{m}^{-2} \mathrm{~s}^{-1}$. Beyond this light intensity, the biomass productivity did not increased anymore. This value of PFD can be taken as a critical point for photosynthetic efficiency or, roughly considered as the light saturation point (LSP) for S. platensis grown in a biofilm. The maximum biomass productivity of $S$. platensis achieved in the present work are almost equivalent to those achieved on mass cultivation scale in open ponds (Jimenez et al., 2003) under solar illumination. It is also worth mentioning that the biomass productivity was also higher than those achieved by other microalgae species, including Aucutodesmus obliquus and Pseudochlorococcum sp., when grown in attached cultivation. The light intensity at LSP of attached S. platensis biofilm was higher than other microalgae species including A. oblique (150 $\left.\mu \mathrm{mol} \mathrm{m}^{-2} \mathrm{~s}^{-1}\right)$ (Liu et al., 2013), Pseudochlorococcum sp. $\left(100 \mu \mathrm{mol} \mathrm{m}^{-2} \mathrm{~s}^{-1}\right)$ (Ji et al., 2014a) indicating that S. platensis is more resistant to strong irradiation.

Nevertheless, it should be noticed that the light intensity at LSP of attached $S$. platensis biofilm was much lower than outdoor solar irradiation (1000-2000 $\left.\mu \mathrm{mol} \mathrm{m} \mathrm{m}^{-2} \mathrm{~s}^{-1}\right)$. This means that if attached S. platensis biofilm was directly exposed under the blazing sun, photoinhibition on algal growth would be very serious, and even the biofilm would be bleached. Therefore, light dilution, as proposed by Liu et al. (2013), is required to avoid the photo inhibition and make full use of solar radiation for biomass synthesis. An attempt to cultivate $S$. platensis in a bench-scale bioreactor with a 10 times light dilution was made and the results will be illustrated in the Section 3.5.

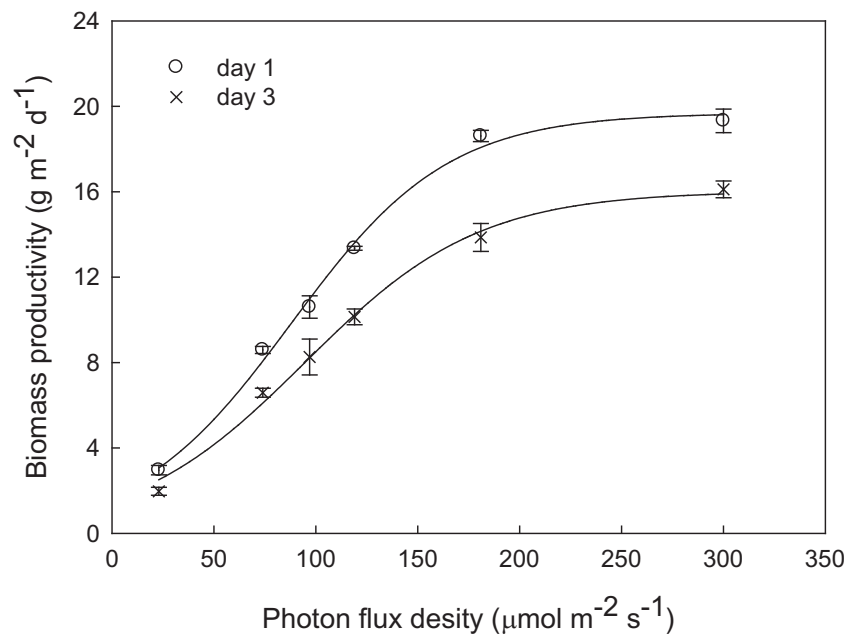

Fig. 3. Effects of photon flux density (PFD) on the biomass productivity of attached S. platensis biofilm. Culture conditions: ca. $23-300 \mu \mathrm{mol} \mathrm{m}^{-2} \mathrm{~s}^{-1}$ range of light intensity, ca.7 $\mathrm{g} \mathrm{m}^{-2}$ of the initial inoculum density, $\mathrm{CO}_{2}$ enriched air $(0.5 \%)$ at $0.0056 \mathrm{~m} \mathrm{~s}^{-1}$ superficial aeration rate, room temperature. Data and error bars represent means \pm SD of three repeats. 
The biomass productivity is also gradually reduced with the prolonging of cultivation time. It may be attributed to the increased thickness of algal biofilm by growth as stated above.

\subsection{The influence of $\mathrm{CO}_{2}$ concentration and aeration rate}

Currently, bicarbonate is used as carbon source for most of the S. platensis cultivation in open ponds. However S. platensis can also use dissolved $\mathrm{CO}_{2}$, which can come in various forms, from pure $\mathrm{CO}_{2}$ to industrial gaseous effluents, a more biocompatible and economic alternative. For attached cultivation, the direct contact between aerated gaseous $\mathrm{CO}_{2}$ and algal biofilm has been validated to effectively provide carbon for algal growth (Liu et al., 2013; Ji et al., 2014a). Similarly, the concentration of $\mathrm{CO}_{2}$ and aeration rate of the aerated gas have critical influence on the attached cultivation. The effect of $\mathrm{CO}_{2}$ concentration on the biomass productivity of attached S. platensis biofilm with $\mathrm{NaHCO}_{3}$ free Zarrouk medium is illustrated in Fig. 4A. When the $\mathrm{CO}_{2}$ concentration increased from $0.038 \%$ (natural atmosphere $\mathrm{CO}_{2}$ concentration) to $0.5 \%$, the biomass productivity quickly increased. Beyond $0.5 \%$ of $\mathrm{CO}_{2}$, the biomass productivity slightly reduced. It means that a $\mathrm{CO}_{2}$ concentration of about $0.5 \%$ represented the optimum. The same trend has also been found with Pseudochlorococcum sp. attached cultivation
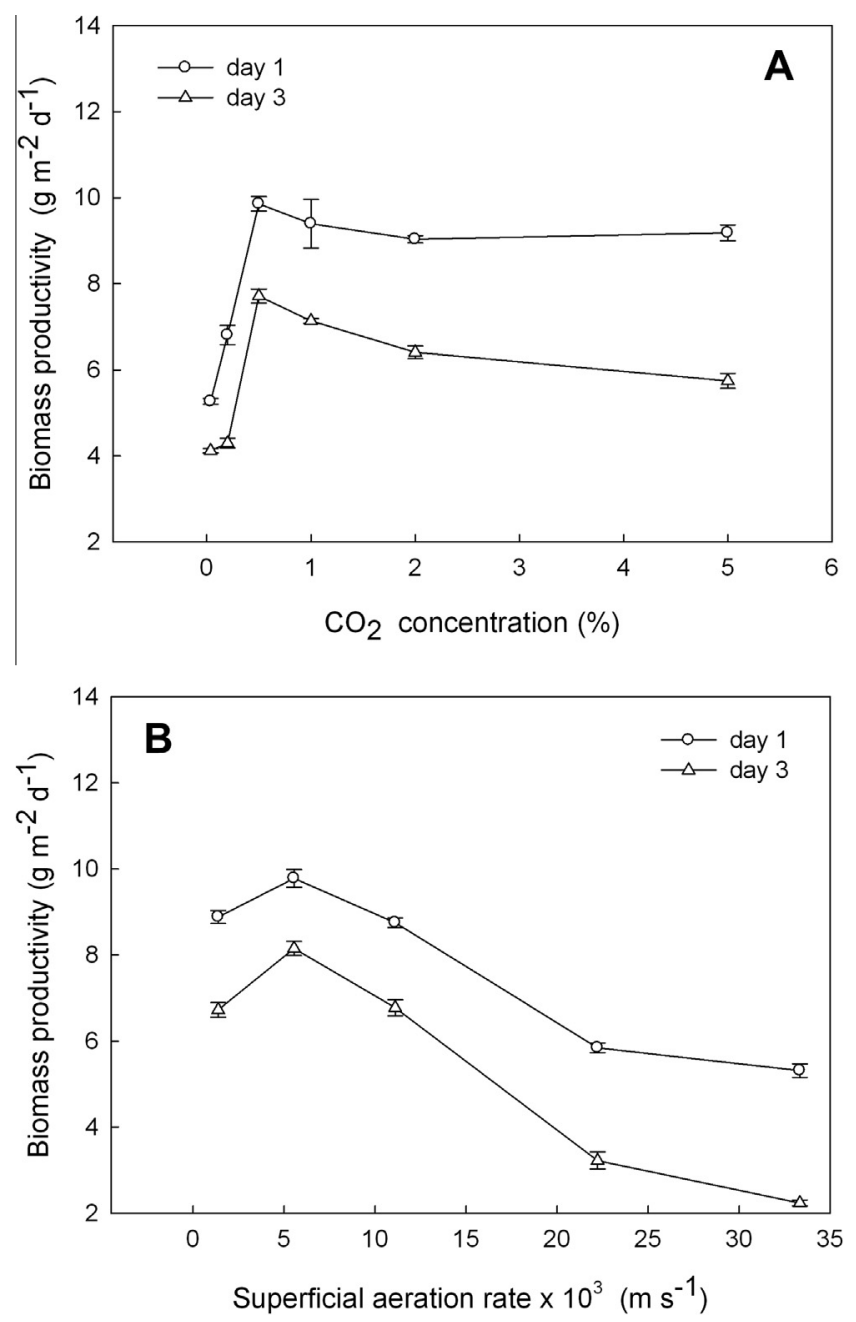

Fig. 4. Effects of $\mathrm{CO}_{2}$ concentration (A) and superficial aeration rate (B) on biomass productivity of attached $S$. platensis with $\mathrm{NaHCO}_{3}$-free Zarrouk medium. Culture conditions: $\mathrm{CO}_{2}$ enriched air (0.5-5\%), $100 \mu \mathrm{mol} \mathrm{m} \mathrm{m}^{-2} \mathrm{~s}^{-1}$ light intensity, and room temperature. Data and error bars represent means \pm SD of three repeats. but in that case the critical $\mathrm{CO}_{2}$ concentration was $1.0 \%$ (Ji et al., 2014a).

Fig. 4B demonstrates that the effect of superficial aeration rate on the biomass productivity of attached S. platensis biofilm. The biomass productivity increased to the maximum value when superficial aeration rate rose to $0.0056 \mathrm{~m} \mathrm{~s}^{-1}$. After that, stronger aeration intensity caused a dramatical reduction of the biofilm growth. It should be considered that Spirulina sp. is a basophilic microalga and consequently prefers high $\mathrm{pH}$ environment. Therefore, an inappropriate aeration condition with too high flow rate and content of $\mathrm{CO}_{2}$ may faintly acidify the contact region between the wet biofilm and the gaseous phase and then inhibit the growth of algal cells (Langley et al., 2012). Thus, an optimal aeration condition is needed in order to balance the benefits related to $\mathrm{CO}_{2}$ supplementation and the risk of physiological stress due to the acidification.

\subsection{The influence of substrata}

In addition of NC membrane, four industrial materials were also used as substrata. The growth of algal biofilm on both EFC and FS seems more active than that on the surface of both SFT and FC, to form varying sizes of visible bubbles on the biofilm due to oxygen-release by photosynthesis. The biomass productivity of algal cells on these four substrata is shown in Fig. 5. It can be seen that EFC has the highest biomass productivity, the FS and SFT have a slight lower biomass productivity, while the FC is the worst.

It was reported that the properties of substrata; in particular, the hydrophilicity/hydrophobicity and the surface structure of substrata, play important roles on growth of algal attached biofilm (Singh, 2011; Cui and Yuan, 2013). The EFC has hydrophilic fluffs on the cloth surface with tiny pores, the FS is made of hydrophilic PVC material, rich of tiny labyrinth pores and shows excellent liquid holding capacity. The SFT is woven by polyester superfine which also has strong hydrophilicity. However, the FC, made of coarse nylon fibers and with big pore size, shows hydrophobicity and bad ability in water retention. In the present work, the three substrata (EFC, FS and SFT) showed better ability than FC on attached cultivation of $S$. platensis, demonstrates that hydrophilic material with tiny pore size and good liquid holding capacity is preferable for the attachment cultivation.

Compared with four industrial substrata, the biomass productivity on NC membrane is slightly higher. Furthermore, the initial inoculums density has to be higher for industrial substrata

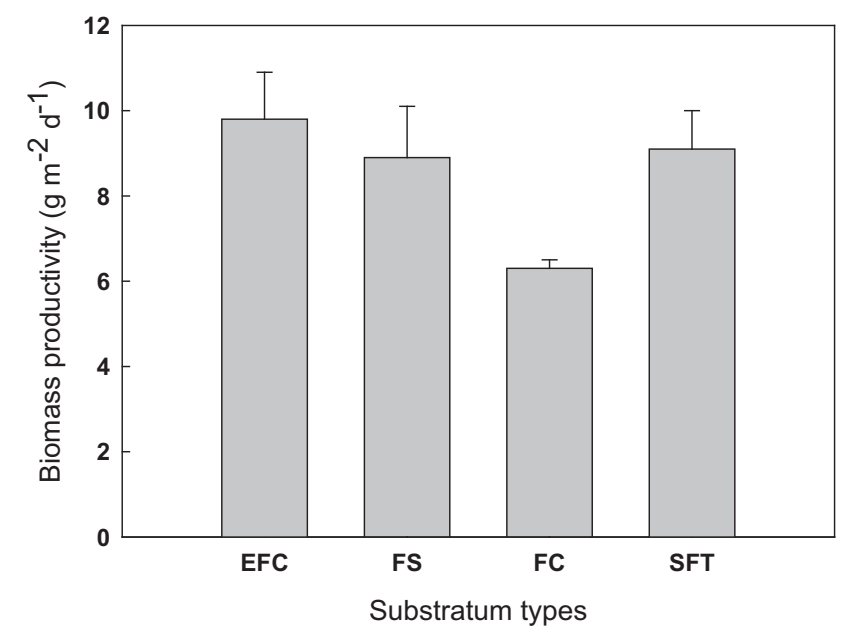

Fig. 5. Effect of industrial substrata on biomass productivity of attached S. platensis. 

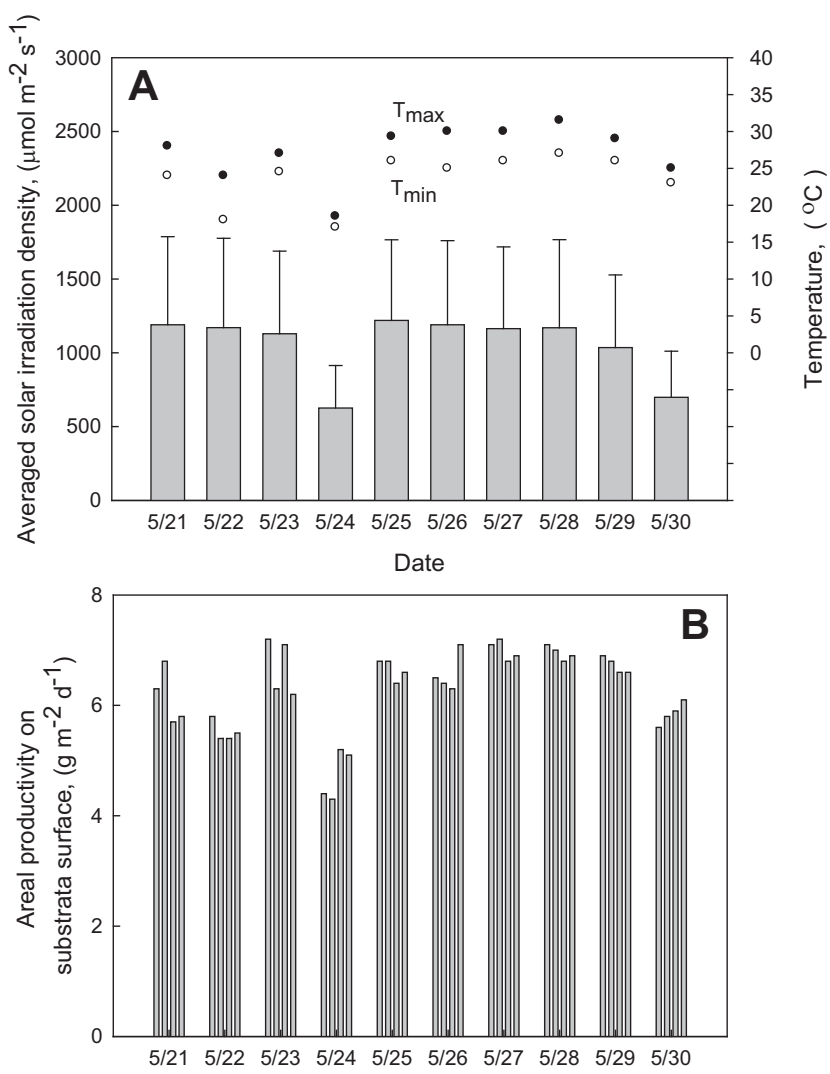

Date

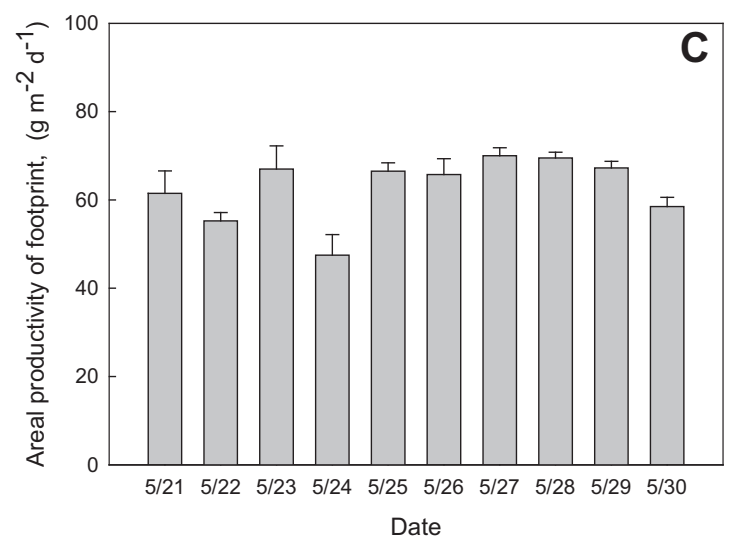

Fig. 6. Outdoor bench-scale attached cultivation of S. platensis. (A) Daily averaged solar irradiation and temperature during experiment. (B) Biomass productivity based on the unit area of the substrate. (C) Biomass productivity based on the footprint area of the bioreactor.

$\left(25 \mathrm{~g} \mathrm{~m}^{-2}\right.$ ) than that usually used for NC membrane, due to the bigger pore size and the rougher surface requiring more algal cells to well cover the surface of the former ones. Nevertheless, NC membrane is not a practicable substratum for mass cultivation, due to be fragile, non durable, expensive, and non-resistive to washingoff of algal cells by medium supplement (Singh, 2011). In additional, FS is the cheapest one but it is not durable when submitted to frequent harvesting by scrapping, and the SFT is the most expensive one among the four tested industrial substrata. Therefore, EFC appears to be the only practicable one for mass attached cultivation of S. platensis.

All in all, the optimum conditions for potential mass cultivation of S. platensis biofilm were, $25 \mathrm{~g} \mathrm{~m}^{-2}$ for initial inoculum density using EFC as substrata, light intensity lower than $200 \mu \mathrm{mol} \mathrm{m} \mathrm{m}^{-2} \mathrm{~s}^{-1}$,
$\mathrm{CO}_{2}$ enriched air flow (air: $\mathrm{CO}_{2}=1: 0.005, v: v$ ) at a superficial aeration rate of $0.0056 \mathrm{~m} \mathrm{~s}^{-1}$ in a $\mathrm{NaHCO}_{3}$-free Zarrouk medium.

\subsection{Cultivation of S. platensis in outdoor bench-scale bioreactor}

In order to practice attached cultivation of S. platensis in a bigger scale, outdoor cultivation experiments in a bench-scale bioreactor, consisted of three pieces of $0.2 \mathrm{~m}^{2} \mathrm{EFC}$ (Fig. 1B), were carried out in early summer of 2012 in Qingdao. Most parameters for attached cultivation, such as substrata, initial inoculum density, superficial aeration rate of $\mathrm{CO}_{2}$, and culture medium, were following the optimum ones obtained from indoor experiments. The $\mathrm{CO}_{2}$ concentration of the aerated gas was doubled of the indoor one, due to considering the fact that the outdoor bioreactor was not well sealed and the cultivation space is far bigger than that occupied by the three EFC. Although the temperature and the PFD were not adjusted to the optimum, these two parameters were recorded during the whole outdoor cultivation period and plotted in Fig. 6A. The averaged PFD was around $1100-1200 \mu \mathrm{mol} \mathrm{m}{ }^{-2} \mathrm{~s}^{-1}$ and the temperature was quite steady around $24-32{ }^{\circ} \mathrm{C}$ in daytime, except for cloudy days on May 24 and 30.

The biomass productivity of algal biofilm was shown in Fig. 6 . The biomass productivity based on unit area of the substrate $\left(P_{\mathrm{g}}\right)$, recorded on the four cultivated surfaces of EFC in different dates, ranged $6-7 \mathrm{~g} \mathrm{~m}^{-2} \mathrm{~d}^{-1}$ (Fig. 6B). This value showed a little variation, due to unstable temperature and PFD during outdoor cultivation. The variation of $P_{\mathrm{g}}$, on the other hand, is probably due to the difference on the amount of harvested algal pastes and on the amount of retained algal cells after manual harvesting, which may influence the next day's growth as aforementioned in the Section 3.1.

The biomass productivities based on the footprint area of the bench-scale bioreactor $\left(P_{\mathrm{f}}\right)$ ranged $46-70 \mathrm{~g} \mathrm{~m}^{-2} \mathrm{~d}^{-1}$ (Fig. 6C), with a maximum of $70 \mathrm{~g} \mathrm{~m}^{-2} \mathrm{~d}^{-1}$ on May 27, during whole outdoor experiment period. The minimum $P_{\mathrm{f}}$ is $46 \mathrm{~g} \mathrm{~m}^{-2} \mathrm{~d}^{-1}$, occurred on May 24, when both PFD and temperature reach the lowest during experiment period.

When culturing Spirulina sp. in water suspension, particularly in open pond, the $P_{\mathrm{f}}$ was usually less than $15 \mathrm{~g} \mathrm{~m}^{-2} \mathrm{~d}^{-1}$ (Jimenez et al., 2003; De Bhowmick et al., 2014). The value obtained from present outdoor attached cultivation is much higher than that recorded from open pond and other PBRs, with the exception for the results by Hu et al. (1998), which was obtained using an extreme thin flat panel under strong illumination.

Comparing with the $P_{\mathrm{f}}$ from other microalgae species cultured as biofilm, the $P_{\mathrm{f}}$ from $S$. platensis is lower than $80 \mathrm{~g} \mathrm{~m}^{-2} \mathrm{~d}^{-1}$ from A. obliquus (Liu et al., 2013), but is much higher than $7.7 \mathrm{~g} \mathrm{~m}^{-2} \mathrm{~d}^{-1}$ from Halochlorella rubescens (Shi et al., 2014) and $20.1 \mathrm{~g} \mathrm{~m}^{-2} \mathrm{~d}^{-1}$ from Chlorella Sorokiniana (Blanken et al., 2014), Nevertheless, all these values are far less than theoretical value of microalgae, $c a$. $120 \mathrm{~g} \mathrm{~m}^{-2} \mathrm{~d}^{-1}$ (Tredici, 2010).

\subsection{Protein, carbohydrate and lipid contents of S. platensis}

The contents of protein, carbohydrate and lipid in S. platensis biomass from attached cultivation and conventional liquid suspension cultivation are listed in Table 1. It can be found that the protein, carbohydrate and lipid contents of S. platensis are around $50 \%$, $12 \%$ and $10 \%$ respectively, when grown in attached cultivation for 1 and $3 \mathrm{~d}$ cultivation. This protein content of $S$. platensis showed a little variation, ranged $41-56 \%$, during whole outdoor cultivation. These values are very close to those values from conventional liquid suspension cultivation. Also, the nutrient component of S. platensis are very close to work of Fedekar et al. (2012), who reported the protein, carbohydrate and lipid contents of $52.9 \%$, $13.2 \%$ and $7.5 \%$ respectively, in liquid cultivation of Zarruk 
Table 1

Protein, carbohydrate and lipid contents of S. platensis with the suspension cultivation and attached cultivation.

\begin{tabular}{|c|c|c|c|c|}
\hline Cultivation methods & Culture time $(\mathrm{d})$ & Crude protein (\% dry weight) & Carbohydrate (\% dry weight) & Lipid (\% dry weight) \\
\hline SPL & 3 & $51.99 \pm 0.48$ & $13.06 \pm 0.39$ & $10.88 \pm 0.65$ \\
\hline SPA & 1 & $48.93 \pm 0.65$ & $12.33 \pm 0.61$ & $10.13 \pm 0.61$ \\
\hline SPA & 3 & $50.89 \pm 0.27$ & $12.65 \pm 0.65$ & $10.73 \pm 0.21$ \\
\hline
\end{tabular}

$\mathrm{SPL}=S$. platensis with suspension liquid cultivation.

$\mathrm{SPA}=$ S. platensis with attached cultivation.

Data represent means \pm SD of two samples.

medium. It indicates that the attached cultivation technique could produce high nutritive product.

\section{Conclusions}

An attached cultivation technique was introduced to cultivate S. platensis in indoor and outdoor environment. The optimum conditions for attached cultivation of $S$. platensis were firstly carried out from indoor experiments. Attached cultivation of S. platensis was successfully implemented in an outdoor bench-scale bioreactor thereafter. A high biomass productivity of $60 \mathrm{~g} \mathrm{~m}^{-2} \mathrm{~d}^{-1}$ for S. platensis was obtained therein. The nutrition of $S$. platensis from attached cultivation technique is same as that from conventional technique. The results demonstrate that the attached cultivation technique is a promising way to greatly improve production of high nutritive $S$. platensis.

\section{Acknowledgements}

This work was supported by the National Natural Science Foundation of China (NSFC) (41276144), the Director Innovation Foundation of Qingdao Institute of Bioenergy and Bioprocess Technology, Chinese Academy of Sciences, and Science and Technology Development Planning of Shandong Province (2013GHY11520).

\section{References}

Ajayan, K.V., Selvaraju, M., 2011. Reflector based chlorophyll production by Spirulina platensis through energy save mode. Bioresour. Technol. 102, 7591-7594.

Association of Official Analytical Chemists (AOAC), 1984. Official Methods of Analysis, 14th ed. DC, USA, Washington (pp. 635-678).

Belay, A., Ota, Y., Miyakawa, K., Shimamatsu, H., 1993. Current knowledge on potential health benefits of Spirulina. J. Appl. Phycol. 5, 235-241.

Bezerra, R.P., Matsudo, M.C., Sato, S., Perego, P., Converti, A., Carvalho, J.C.M., 2012. Effects of photobioreactor configuration, nitrogen source and light intensity on the fed-batch cultivation of Arthrospira (Spirulina) platensis. Biomass Bioenergy 37, 309-317.

Blanken, W., Janssen, M., Cuaresma, M., Libor, Z., Bhaiji, T., Wijffels, R.H., 2014. Biofilm growth of Chlorella Sorokiniana in a rotating biological contactor based photobioreactor. Biotechnol. Bioeng. 111, 2436-2445.

Chen, C.Y., Yeh, K.L., Aisyah, R., Lee, D.J., Chang, J.S., 2011. Cultivation, photobioreactor design and harvesting of microalgae for biodiesel production: a critical review. Bioresour. Technol. 102, 71-81.

Chen, L., Liu, T.Z., Zhang, W., Chen, X.L., Wang, J.F., 2012. Biodiesel production from algae oil high in free fatty acids by two-step catalytic conversion. Bioresour. Technol. 111, 208-214.

Converti, A., Lodi, A., Borghi, A.D., Solisio, C., 2006. Cultivation of Spirulina platensis in a combined airlift-tubular reactor system. Biochem. Eng. J. 32, 13-18.

Cui, Y., Yuan, W.Q., 2013. Thermodynamic modeling of algal cell-solid substrate interactions. Appl. Energy 112, 485-492.

De Bhowmick, G., Subramanian, G., Mishra, S., Sen, R., 2014. Raceway pond cultivation of a marine microalga of Indian origin for biomass and lipid production: a case study. Algal Res. 6, 201-209.

Dubois, G., Gilles, K.A., Hamilton, S.K., Rebers, P.A., Smith, F., 1956. Colorimetric method for determination of sugars and related substances. Anal. Chem. 28 (3), 350-356.
Fedekar, F.M., Abd, El-W.K. Hoda, S.N., 2012. Production and nutritive value of Spirulina platensis in reduced cost media. Egypt. J. Aquat. Res. 38, 51-57.

Gross, M., Wen, Z., 2014. Yearlong evaluation of performance and durability of $a$ pilot-scale revolving algal biofilm (RAB) cultivation system. Bioresour. Technol. $171,50-58$

Guo, F.J., Wang, H., Wang, J.F., Zhou, W.J., Gao, L.L., Dong, Q.Z., Zhang, W., Liu, T.Z., 2014. Special biochemical responses to nitrogen deprivation of filamentous oleaginous microalgae Tribonema sp. Bioresour. Technol. 158, 19-24.

Guterman, H., Vonshak, A., Ben-Yaakow, S., 1990. A macro model for outdoor algal mass production. Biotechnol. Bioeng. 35, 809-819.

Hu, Q., Zarmi, Y., Richmond, A., 1998. Combined effects of light intensity, light-path and culture density on output rate of Spirulina platensis (Cyanobacteria). Eur. J. Phycol. 33, 165-171.

Ji, B., Zhang, W., Zhang, N., Wang, J.F., Lutzu, G., Liu, T.Z., 2014a. Biofilm cultivation of the oleaginous microalgae species Pseudochlorococcum sp. Bioprocess Biosyst. Eng. 37, 1369-1375.

Ji, C.L., Wang, J.F., Zhang, W., Liu, J.L., Wang, H., Gao, L.L., Liu, T.Z., 2014b. An applicable nitrogen supply strategy for attached cultivation of Aucutodesmus obliquus. J. Appl. Phycol. 26, 173-180.

Jimenez, C., Cossio, B.R., Niell, F.X., 2003. Relationship between physicochemical variables and productivity in open ponds for the production of spirulina: a predictive model of algal yield. Aquaculture 221, 331-345.

Langley, N.M., Harrison, S.T.L., van Hille, R.P., 2012. A critical evaluation of $\mathrm{CO}_{2}$ supplementation to algal systems by direct injection. Biochem. Eng. J. 68, 7075.

Larkum, A.W.D., 2010. Limitations and prospects of natural photosynthesis for bioenergy production. Curr. Opin. Biotechnol. 21, 271-276.

Lee, Y.K., 1986. Enclosed bioreactor for the mass cultivation of photosynthetic microorganisms: the future trend. Trends Biotechnol. 4, 186-189.

Liu, T.Z., Wang, J.F., Hu, Q., Cheng, P.F., Ji, B., Liu, J.L., Chen, Y., Zhang, W., Chen, X.L. Chen, L., Gao, L.L., Ji, C.L., Wang, H., 2013. Attached cultivation technology of microalgae for efficient biomass feedstock production. Bioresour. Technol. 127, 216-222.

Madkour, F.F., Kamil, A.E.W., Nasr, H.S., 2012. Production and nutritive value of Spirulina platensis in reduced cost media. Egypt. J. Aquat. Res. 38, 51-57.

Naumann, T., Cebi, Z., Podola, B., Melkonian, M., 2013. Growing microalgae as aquaculture feeds on twin-layers: a novel solid-state photobioreactor. J. Appl. Phycol. 25, 1413-1420.

Ozkan, A., Kinney, K., Katz, L., Berberoglu, H., 2012. Reduction of water and energy requirement of algae cultivation using an algae biofilm photobioreactor. Bioresour. Technol. 114, 542-548.

Shen, Y., Chen, C., Chen, W., Xu, X., 2014. Attached culture of Nannochloropsis oculatc for lipid production. Bioprocess Biosyst. Eng. 37, 1743-1748.

Shi, J., Podola, B., Melkonian, M., 2014. Application of a prototype-scale Twin-Layer photobioreactor for effective $\mathrm{N}$ and $\mathrm{P}$ removal from different process stages of municipal wastewater by immobilized microalgae. Bioresour. Technol. 154, 260-266.

Singh, S., 2011. Methodology for membrane fabric selection for pilot-bioreactor (Thesis of the faculty of the Russ College of Engineering and Technology). Ohio University.

Soletto, D., Binaghi, L., Lodi, A., Carvalho, J.C.M., Converti, A., 2005. Batch and fedbatch cultivations of Spirulina platensis using ammonium sulphate and urea as nitrogen sources. Aquaculture 243, 217-224.

Tomaselli, L., Giovannetti, I., Margheri, M.C., 1981. On the mechanism of trichome breakage in Spirulina platensis and S. maxima. Ann. Microbiol. 31, 27-33.

Tredici, M.R., 2010. Photobiology of microalgae mass cultures: understanding the tools for the next green revolution. Biofuels 1, 143-162.

Wijffels, R., Barbosa, M., 2010. An outlook on microalgae biofuels. Science 329, 796 799.

Wuertz, S., Bishop, P.L., Wilderer, P.A., 2003. Biofilms in Wastewater Treatment: An Interdisciplinary Approach. IWA Publishing, London.

Zarrouk, C., 1966. Contribution to the study of a Cyanophycea: influence of various physical and chemical factors on the growth and photosynthesis of Spirulina platensis (Thesis). University of Paris. 